\title{
Anticoagulation management during cardiopulmonary bypass: A survey of 54 North American institutions
}

\author{
Robert L. Lobato, MS, MD, ${ }^{\mathrm{b}}$ George J. Despotis, MD, ${ }^{\mathrm{c}}$ Jerrold H. Levy, MD, ${ }^{\mathrm{d}}$ \\ Linda J. Shore-Lesserson, MD, ${ }^{\mathrm{e}}$ Melvin O. Carlson, MSc, ${ }^{\mathrm{f}}$ and Elliott Bennett-Guerrero, MD, ${ }^{\mathrm{a}}$ \\ Durham, NC, St. Louis, Mo, Atlanta, Ga, Bronx, NY, and Framingham, Mass
}

Despite evidence-based guidelines for blood conservation in cardiac surgery, ${ }^{1}$ the clinical management of anticoagulation during cardiopulmonary bypass (CPB) is not standardized. This is further complicated by the fact that patients' responsiveness to heparin is variable. Impaired heparin responsiveness or "heparin resistance" is often the result of patient-specific causes, such as antithrombin deficiency or high concentrations of heparin-binding proteins, but can also be due to the heparin formulation itself. In clinical practice inhibiting thrombin formation/activity during CPB is essential to minimizing overt thrombosis, the clinical consequences of a consumptive coagulopathy, or both.

A survey of anticoagulation practices, published in $1999,{ }^{2}$ observed significant variability in practice with reported acceptable activated clotting times (ACTs) ranging from 240 to 1000 seconds. The purpose of the present analysis a decade later is to characterize current anticoagulation management strategies for $\mathrm{CPB}$.

\section{CLINICAL SUMMARY}

After institutional review board approval, an 18-question written survey was distributed by e-mail to 162 academic and nonacademic institutions in the United States and Canada in 2008. The survey was conducted by the Duke Clinical Research Institute (Durham, NC) and sponsored by GTC Biotherapeutics, Inc (Framingham, Mass). Surveys were sent to a cardiac surgeon or cardiac anesthesiologist at each site, and respondents were asked to comment on current practice. Summary data were calculated and are presented as percentages of completed survey questionnaires. GTC Bio-

\footnotetext{
From the Duke Clinical Research Institute, ${ }^{\mathrm{a}}$ Duke University Medical Center, ${ }^{\mathrm{b}}$ Durham, NC; Washington University School of Medicine, ${ }^{c}$ St. Louis, Mo; Emory University Hospital, ${ }^{\mathrm{d}}$ Atlanta, Ga; Montefiore Medical Center, ${ }^{\mathrm{e}}$ Bronx, NY; and GTC Biotherapeutics, Inc, ${ }^{\mathrm{f}}$ Framingham, Mass.

Supported by GTC Biotherapeutics, Inc.

Disclosures: M. O. Carlson is an employee of GTC Biotherapeutics, Inc. G. J. Despotis, J. H. Levy, L. J. Shore-Lesserson, and E. Bennett-Guerrero have been paid consultants of GTC Biotherapeutics, Inc. E. Bennett-Guerrero received research funding through the Duke Clinical Research Institute to conduct this survey.

Received for publication Dec 15, 2009; revisions received Jan 29, 2010; accepted for publication Feb 22, 2010; available ahead of print March 22, 2010.

Address for reprints: Elliott Bennett-Guerrero, MD, Duke Clinical Research Institute, Duke University Medical Center (Box 3094), Durham, NC 27710 (E-mail: Elliott. BennettGuerrero@Duke.edu).

J Thorac Cardiovasc Surg 2010;139:1665-6

$0022-5223 / \$ 36.00$

Copyright $@ 2010$ by The American Association for Thoracic Surgery

doi:10.1016/j.jtcvs.2010.02.038
}

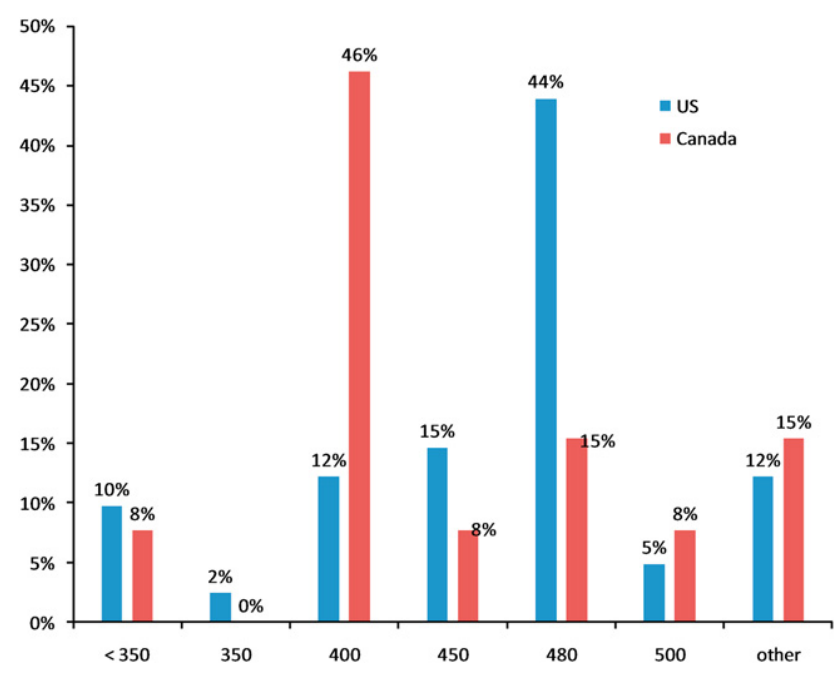

FIGURE 1. Target activated clotting time (ACT) before instituting cardiopulmonary bypass (CPB). The $x$-axis shows the value for target ACT before instituting $\mathrm{CPB}$, and the $y$-axis shows the percentage of sites reporting that particular target value.

therapeutics, Inc, provided input into the development of survey questions but was not involved in the collection or analyses of data. No compensation was provided to respondents. The manuscript was drafted by the Duke Clinical Research Institute and was reviewed by all authors, including a representative from the sponsor (MOC).

Of the 162 surveys sent, responses were received from 54 $(33 \%)$ sites. Forty-one of these institutions were located within the United States, and 13 were located in Canada. Overall, $43 \%$ (23/54) of sites performed 500 or fewer cases with CPB annually, whereas $24 \%$ (13/54) of sites performed more than 1000 cases with CPB annually.

For US respondents, $78 \%$ used empiric weight-based dosing to guide the initial heparin dose compared with $100 \%$ of Canadian institutions, and $22 \%$ of US institutions used an in vitro heparin dose-response method to determine the initial heparin dose. The target ACT for instituting CPB ranged from less than 350 seconds to 500 seconds (Figure 1). However, a majority of institutions used a value of between 400 and 480 seconds (ie, $71 \%$ for US sites and $69 \%$ for Canadian sites). The maximum heparin dose administered to achieve the target ACT before considering supplemental therapies (eg, plasma or antithrombin concentrate) is shown in Figure 2, with $57 \%$ of US and $77 \%$ of Canadian centers using a value of $500 \mathrm{IU} / \mathrm{kg}$ or greater. 


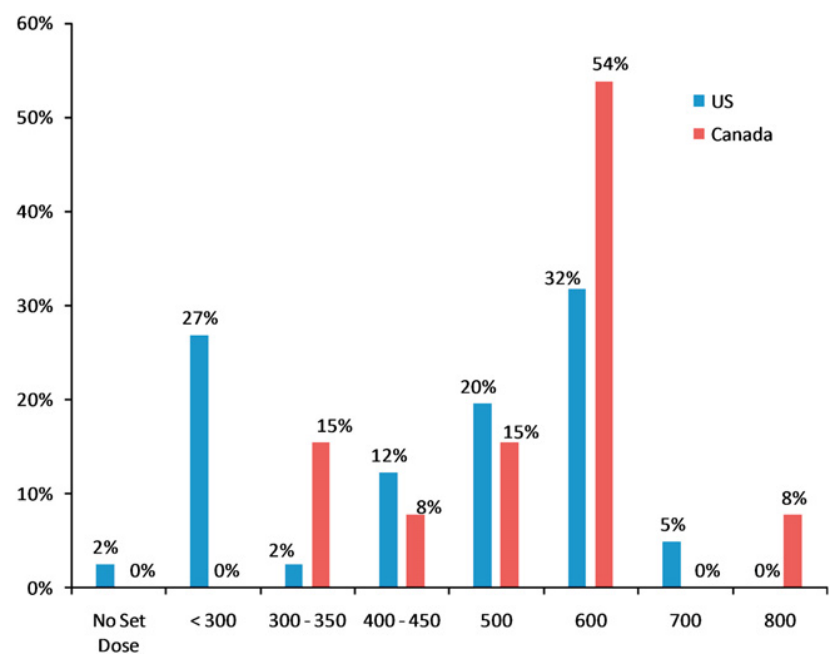

FIGURE 2. Maximum heparin dose before considering alternatives (fresh frozen plasma or antithrombin concentrate). The $x$-axis shows the value for total heparin dose in units per kilogram body weight before considering alternatives, such as fresh frozen plasma or antithrombin concentrate, and the $y$-axis shows the percentage of sites reporting a maximum total heparin dose.

Heparin resistance was sometimes or always treated with fresh frozen plasma in $85 \%$ of US sites. Heparin resistance was sometimes or always treated with antithrombin concentrate in $46 \%$ of US sites surveyed. Canadian institutions used mostly fresh frozen plasma $(85 \%)$, and only $1(8 \%)$ site used antithrombin concentrate to treat heparin resistance.

In addition, for CABG surgery with $\mathrm{CPB}, 95 \%$ of US sites used $\epsilon$-aminocaproic acid (EACA), but no Canadian site surveyed used EACA. Only 7 (17\%) US sites used tranexamic acid in contrast to $100 \%$ of Canadian sites.

\section{DISCUSSION}

Despite several decades of cardiac surgery with heparinbased anticoagulation for $\mathrm{CPB}$, the target ACT that confers a level of safe anticoagulation has not been universally defined; however, an ACT that approximates 400 to 480 seconds is most commonly used. Our survey demonstrates that there is still variability in the management of heparinbased anticoagulation for CPB, yet there is even more variability in the diagnosis and management of heparin resistance. Previous studies have shown that heparin resistance occurs in a small percentage of patients. This low incidence might explain the paucity of literature aimed at assessing the optimal therapy for this problem. 3,4

It is also notable that most $(95 \%)$ US centers use the lysine analogue EACA, whereas Canadian centers exclusively used tranexamic acid. The Blood Conservation Using Antifibrinolytics in a Randomized Trial (BART) study demonstrated no clear superiority of one lysine analogue over the other. ${ }^{5}$ These differences in use are regional and might reflect economic or political factors or variable interpretation of the literature. All surveys have inherent limitations, including selection bias and nonresponse bias. Despite a modest response rate, we obtained survey data from a relatively large number of sites, which increases the ability to generalize our findings.

In summary, our survey of 54 North American sites reveals significant variability with respect to anticoagulation practices. More studies are needed to determine whether this variability in care is of clinical relevance.

\section{References}

1. Ferraris VA, Ferraris SP, Saha SP, et al. Perioperative blood transfusion and blood conservation in cardiac surgery: the Society of Thoracic Surgeons and The Society of Cardiovascular Anesthesiologists clinical practice guideline. Ann Thorac Surg. 2007;83(suppl):S27-86.

2. Despotis GJ, Gravlee G, Filos K, Levy J. Anticoagulation monitoring during cardiac surgery: a review of current and emerging techniques. Anesthesiology. 1999;91:1122-51.

3. Avidan MS, Levy JH, van Aken H, et al. Recombinant human antithrombin III restores heparin responsiveness and decreases activation of coagulation in heparinresistant patients during cardiopulmonary bypass. J Thorac Cardiovasc Surg. 2005;130:107-13.

4. Williams MR, D'Ambra AB, Beck JR, et al. A randomized trial of antithrombin concentrate for treatment of heparin resistance. Ann Thorac Surg. 2000;70: 873-7.

5. Fergusson DA, Hebert PC, Mazer CD, et al. A comparison of aprotinin and lysine analogues in high-risk cardiac surgery. N Engl J Med. 2008;358:2319-31. 